\title{
Local Undergraduate Normal College Teachers' Pre-Service Education Problem Analysis and Thinking Path
}

\author{
Miao Fu \\ Chongqing College of Education, Chongqing, 400065, China
}

Keywords: Local undergraduate normal colleges. Teachers' pre-service education. Problems. Methods

\begin{abstract}
Local undergraduate normal colleges is the main body of teachers' pre-service education in our country, which provides a solid guarantee for Overall planning for urban-rural development foundation education teachers equilibrium configuration. Local undergraduate normal colleges are faced with both opportunities and challenges in terms of teachers' pre-service education. In order to intensify normal characteristic and meet the demand of professionals needs in the curriculum reform of basic education, their development paths involves: cultivate the teachers' pre-service education oriented on markets; unify curriculum; create practical environment; strengthen administrative department for education and collaborative partnership with primary schools and universities; establish teachers' pre-service education community ; enhance education level ; make professionals “double-teacher”.
\end{abstract}

\section{Introduction}

In Oct. 2011, “Curriculum standards of professional-education” (referred as to Standards) issued by Ministry of Education showed a sign that Chinese professional-education reformation made a new step. Local undergraduate normal colleges are the main body of teachers' pre-service education in our country with the background of" professional-education integration "and overall planning for urban-rural development. Local undergraduate normal colleges are faced with both opportunities and challenges in terms of teachers' pre-service education. It is incredible to study how to implement the perception of "practice orientation, attaching most importance to capacity" proposed by Standards, and to analyse the problems existing in the current local higher education institutions and explore the methods.

\section{The analysis of the teachers' pre-service education in local undergraduate normal colleges}

\section{Pedagogical characteristic become less prominent and major setup more identical}

The talent cultivation gist of normal colleges is high-level and professional teachers necessary for develop basic education. With enrollment scale increasingly expanded, employment situation increasingly severe and new major developing quickly, characteristics of local undergraduate normal colleges are more likely to dim. It embodies in following aspects: Firstly the proportion of non-normal major increasingly outnumber the normal major ,which is take up the educational resources for normal major. For example, one educational college, escalated to general undergraduate college in 2011, has less than 30\% professional majors. The proportion of expenditure for normal school major is less than $10 \%$ in the process of construct experimental training work. Secondly major setups are becoming more identical and it is difficult to form its college feature. Aiming at corresponding local primary education institution setup, accommodate basic educational subject and demand for new teachers, major setups homogenous is prominent. This problem triggers talent cultivation factory-like which makes the paradox between graduates' ability and capacity and teacher demand for basic education more severe. For example ,in order to adapt to social ,science and other integrated subjects in primary schools, each local undergraduate normal colleges set up following subject, Chinese, English, Math, politics, physics, chemistry, computer science and so forth. 
Therefore the supply outnumbers the demand in terms of enrollment scale and a number of pedagogical graduates have to escape from their field.

\section{Pedagogical characteristics in curriculum structure are not outstanding; the implementation effect is not excellent}

"Standard" is the first teacher training curriculum standards in our country. It forms three basic perceptions: most value educates people, practice orientation, lifelong learning. These three beliefs reflect contemporary teacher-education curriculum view in our country. With normal colleges putting "Standard" into practice, some big changes occur in terms of structure and content in teachers' pre-service education. Some gaps, however, exist in teacher-education curriculum and implementation. It is likely to be observed in the following sides: Firstly, the proportion of curriculum structure is not balanced. There exists the phenomena that value subject curriculum more than general pedagogical curriculum. Some research data shows that in local teacher-education curriculum, the proportion of teacher-education class hours is $10 \%$, subject curriculum is $54 \%$, independent practical curriculum is $12 \%$, which is behind from foreign developing countries. In India, for example, teachers' pre-service education includes four parts, educational theory curriculum (40\%), content of courses and methods (20\%), educational practices(20\%), practical work(20\%). Secondly, the implementation effect is in low level. Questionnaire surveys show that normal school students' degree of satisfaction for teacher-education curriculum is less than $40 \%$, mainly because theory do not keep pace with practice and teachers' effort seriously insufficient in terms of arousing students' learning interest.

Teaching practice organization and management unbalanced, internship and practical training effect is unconspicuous

Organization leadership in teachers' pre-service education in our country is constantly based on normal schools. pre-service educators have no rights on decision and educational expenditures while normal schools not engaging in primary and secondary schools education control the pre-service education learning their experiences. The orientation of teacher cultivated whether accord with the requirement of elementary education curriculum reform, the tester should be experienced teachers or principals of primary and secondary schools. Teaching practice organization and management dislocation will inevitably weaken the practice teaching effect, embodied in the following respects. Firstly, Normal universities intern, trainee plan don't adapt to the teaching practice of primary and secondary schools. Secondly, accepting the teaching practice of teachers' enthusiasm in primary and secondary schools is not high. Thirdly, guide teachers cope with job without the whole heart, worrying about impairing their teaching effects. Fourthly, it is hard for prospective teachers to adapt to the primary and secondary school teachers group, to real experience, and to understand teachers' work. According to the survey, the problem generally reflected by students is eager to mount the stage of the teaching field. But due to a number of reasons, their dreams do not come true. Prospective teachers are still unfamiliar with the concept of new curriculum reform, the basic norms and effective classroom management in the trial lecturing.

\section{Lack of "double type" teachers, teaching practice guidance is ineffective}

With increasing college expansion, the demand for teachers is growing. The enrollment expansion of graduate students and doctoral student provides rich human resources for colleges and universities to select talents. At the same time, however, normal teaching practice courses and internship trainee teachers lack front-line work experience on basic education, and there exists a defect that education theory do not keep pace with education teaching practice.

According to the survey, students are looking forward to in-service education which has more access to basic education experience, and they have low satisfaction about teaching practice curriculum (only 12\%). An investigation of school students on knowledge about the new curriculum reform shows that, the proportion of $67 \%$ have just heard of it, $13 \%$ almost never learned. In the process of guide practice and practice teaching, one teacher is nearly responsible for more than 100 students , just involve the guidance of student's security issues, therefore the actual guidance almost totally dependent on primary and secondary school teachers. It is hard to achieve the goal on students' guidance from college teaching practice course instructor. The reason can be roughly 
summed up in teachers' pre-service education "double division type" insufficient number of teachers and professional level is not high. Discussing the reasons, not to mention that some students obtain certificate just rely on pedagogy, psychology, mandarin which are regarded as "old three things" . One participating in short-term test training and get qualified grades can obtain certificate.

\section{Local undergraduate colleges and universities teachers' pre-service education path selection}

\section{To strengthen the pedagogical features, guided by the "market" development of teachers' pre-service education}

Local undergraduate normal subject development areas, on the one hand, to adapt to the market demand to expand pays great attention to the school connotation development; On the other hand, the normal professional ratio increases day by day, embodies the "isomorphic" trend of development of the discipline. Teacher education is discipline an double major characteristics of education, its pedagogical features should not be weakened but should be enhanced, guided by the "market" setting. The "market" for local normal universities teacher education is the practical needs of reforms of the foundation education course, basic education need high level and professional teachers. Elementary education new curriculum reform has passed more than ten years, curriculum structure, curriculum content, teaching methods, learning methods have substantially changed. Main choices of local normal universities graduate employment is to teach in the primary and secondary schools. Teachers' pre-service education guided by the "market" development needs teachers' pre-service education connotation development of normal major setting, curriculum structure, teaching content, teaching methods, students skills and teaching practices.

\section{Summarize the curriculum and creating practical environment}

In response to the challenges of The Times, to meet the further development of elementary education new curriculum reform in the new situation, teachers' pre-service education curriculum structure need to plan as a whole, highlight the characteristics of normal and practicality. The capital normal university has attempted to reform the system of teacher education curriculum and has constructed a new education curriculum system including education theory, education practice, education scientific research base, scientific research basis and the education internship trainee. To revolutionize education classes empty and the serious divorcing from reality, the new course program specifically designed for practical course, combining the curriculum and practice and practice trainee etc. with the real practice to meet the students' demand of participating in the practice and understanding the desire of the reality, and at the same time they managed to actually experience the teaching method of "learning by doing". In the organization and arrangement of courses, we need to pay attention to the course content of the plate on the longitudinal association between reflect "sequence" and horizontal integration.

From the perspective of a good rider course of five levels, the ultimate foothold is the 5th level students experience course. And wiithout the creation of practical environment, it is hard to enrich the modern curriculum.

To some extent, the merits of the practical environment determine the success or failure of education practice. All aspects of the normal universities internal also constitute a certain environment, including the campus from two main aspects, such as atmosphere and condition of equipment will directly affect the development of students' education practice and quality.

Such as make full use of the practice base in the freshman to junior school students to carry out the "open week", between "I" growing together with the new curriculum reform, such as "teaching practice contest" activities, understand the dynamics of elementary education new curriculum reform, to encourage students to basic education curriculum reform on the line, into the real classroom, encourage "new courses reform" little research.

To strengthen the cooperation of education administrative departments, primary and secondary schools and universities and build a community of teachers' pre-service education.

The relationship of primary and secondary schools and normal universities with teachers' pre-service education is essentially a partnership. Britain's education minister clark (1992) Klarke, 
emphasis on "primary and secondary school teachers training should be based on a partnership, primary and secondary school teachers to play a leading role in the cultivation of students, from curriculum design to the students' performance appraisal". Based on common vision of education development, the education administrative departments, schools and colleges and universities need to establish a collaborative partnership and build a community of teachers' pre-service education, forming education resultant force. The construction of teachers' pre-service education community may need the individual and mutual cooperation of administrative department of education, primary and secondary schools and normal universities and also need the organization and management of dislocation and inversion. One is the education administrative department of the good organization and coordination of primary and secondary schools and normal universities experts, presided over by formulating the teachers' pre-service education plan; Responsible for the reasonable allocation of teachers' pre-service education funds, primary and secondary schools in the receiving students internship trainee should have special funds; Responsible for coordinating the relationship between the primary and secondary schools and normal universities. Second, the small and medium-sized school teachers' pre-service education work should be brought into the school plan; Determine the experienced teachers in teaching practice guidance teachers, create a harmonious learning atmosphere of cooperation, effectively organize prospective teachers in the teaching field study implementation, to participate in a variety of teaching and researching activities; On teachers' pre-service education fund special fund is special, is responsible for the prospective teachers' life and study, teaching practice guidance; Responsible for timely feedback real student teaching practice condition, equitably to intern, trainee students' performance appraisal. Three is normal colleges aim at the training of professional disciplines and education theory of teachers are supposed to be a good leading role, aimed at teachers' pre-service education being a good supporting role. Prospective teachers' teaching practice of main purpose is to learn, primary and secondary school education teaching experience, and education of primary and secondary schools teaching experience and the living and the owners are primary and secondary schools. Normal universities need to actively participate in the primary and secondary school education, teaching, research, collect feedback opinion and the suggestion, timely adjust the revised teachers' pre-service education program, the students intern, trainee programme.

\section{Improve the level of teacher education faculty, make "double type" teachers}

To strengthen the teachers' pre-service education practice must become the teacher education theme, complete training system construction and the high quality of teacher education faculty prominent teacher education practice as well as the key. The gap of guiding students in colleges and universities teaching practice of training teachers' quality and the elementary education new curriculum reform requires has been criticized by social. To overall improve the level of training teachers, building "double type" teachers can begin from the following aspects: firstly, we should refer to vocational education "double type" teachers' cultivation and strengthen the effectiveness of teacher education teacher training. Only if the college teachers in basic education teaching field fully understand the basis of the education practice, they will know how to train qualified primary and secondary school teachers. Local undergraduate normal colleges teachers usually directly go to teach in colleges and universities after graduating from college. And they often 'theory to the theory', lacking the support of education practice. According to subject characteristics and practical needs, normal colleges could cultivate the backbone teachers by sending relevant teachers in the teacher education faculty in partial phases to primary and secondary school to engage in teaching, management and scientific research. Secondly, we can rich teacher education teachers' source by breaking the talent introduction degree and title bottleneck. In addition to strengthen in-service teacher training in teachers colleges, we also needs to ntroduce and hire the normal system of experts, experts and the backbone of primary and secondary schools teaching, teacher to guide the students' practice teaching link. Thirdly, we should take full advantage of in-service teacher training mainly in local normal colleges to carry out the opportunity and use the resources. Such as in-service teachers cultivating plan, the backbone of primary and secondary school teachers training, the training of the principal project opportunities, to train teachers please into subject, research field, etc., let the 
teachers and students learn, feel, the education idea of the teachers, principals, and teaching practice wisdom.

\section{Acknowledgments}

This article for national social science fund project, the name: "The perspective of urban and rural society to plan as a whole to promote the western urban and rural compulsory education balanced development countermeasures study”.

\section{References}

[1] Chongqing normal university Chinese language and literature of normal undergraduate talent training scheme, 2009, http://wenku.baidu.com/view/4dea6303cc1755270722081e.html

[2] The international comparison of teacher's professional development. Beijing: Education Science Press, 2010: 162.10.

[3] Yuguo Liang: The problem analysis and reconstruction of teachers' pre-service education idea,Journal of Inner Mongolia normal university (education science edition)2010(2):1.

[4] Xuyu Zhen: Pre-service teacher education curriculum reform and the idea of the structure-The capital normal university teacher education professional education courses in transitional scheme design, Curriculum, teaching materials, teaching, 2003(7):50-57. 